\title{
INTERDISCIPLINARIDADE E USO DA LITERATURA NAS AULAS DE HISTÓRIA PARA O ENSINO MÉDIO
}

Irenice de Oliveira Silva Santos ${ }^{1}$

Edésia Aparecida Lisboa de Araújo²

\section{RESUMO}

O presente artigo é fruto de uma pesquisa de Mestrado em andamento que estuda a possibilidade de se utilizar a literatura como método de ensino nas aulas de história do Ensino Médio. Procura mostrar quem são os sujeitos que frequentam o Ensino Médio hoje no Brasil, os desafios que os professores tem para ensinar a esses jovens tão diversos entre si, bem como a importância da leitura para a formação do estudante como cidadão crítico. A partir da importância da leitura, busca explicar a relação entre a história e a literatura com vistas à utilização desta última como recurso didático para as aulas de história. Por meio de um estudo bibliográfico de autores que relacionam as duas áreas do conhecimento, discute questões acerca do campo de atuação das duas disciplinas sob a ótica da interdisciplinaridade.

Palavras-chave: Ensino Médio. Interdisciplinaridade. Jovens.

1 Mestranda em Ciências da Educação pelo Programa de Postgrado da FICS Facultad Interamericana de Ciencias Sociales - Assunção - Paraguai. Atua como professora da Educação Básica da Rede Estadual de Ensino no município de luiu - BA, Brasil. E-mail: irenicegbi@yahoo.com.br Fone: 5577 99173-5532

2 Mestranda em Ciências da Educação pelo Programa de Postgrado da FICS Facultad Interamericana de Ciencias Sociales - Assunção - Paraguai. E-mail: edesialisboa07@gmail.com Fone: 5577 99966-8042 


\section{INTRODUÇÃO}

O Ensino Médio no Brasil, antes frequentado por jovens pertencentes aos grupos sociais mais abastados, hoje, mais popular, apesar de ainda não acessível a todos em idade de estarem matriculados nessa modalidade de ensino, contempla um grupo muito maior e mais diversificado de jovens.

Essa diversidade de alunos em uma mesma sala de aula exige do professor uma diversidade de métodos que possam contemplar as expectativas e as necessidades de todos da melhor forma possível.

Os jovens atualmente tem muito acesso às informações, mas a quantidade estupenda de notícias que bombardeiam os celulares, computadores e televisores exigem do leitor certo grau de criticidade com vistas à seleção dessas informações, filtrando os assuntos relevantes. Daí a importância de desenvolver o hábito de ler, visando à formação do senso crítico, possibilitando ou aprimorando as competências e habilidades necessárias para a formação de um cidadão consciente do seu papel.

Partindo dessa necessidade, pensou-se em utilizar a literatura, em forma de romance, como recurso didático nas aulas de história. Apesar de seus objetivos serem distintos, a história deve informar enquanto a literatura deve entreter, na segunda existem aspectos da sociedade retratada no romance, situada em um lugar e tempo específicos.

A partir do conceito de representação definido por Roger Chartier, buscase utilizar a literatura como ferramenta para o acesso ao conhecimento histórico, pois a literatura pode ser observada como uma representação da realidade.

Nessa perspectiva, através dos elos entre ambas as áreas do conhecimento, desenvolve-se um trabalho interdisciplinar, na medida em que se une o que as duas áreas tem em comum, sem que nenhuma delas perca as suas particularidades. 


\section{O ENSINO MÉDIO E SEUS SUJEITOS}

Até algumas décadas atrás, o público do Ensino Médio era, segundo ARROYO (2014, p. 59), "em sua grande maioria, os jovens dos setores 'médios e altos'." A educação, apesar de pública e gratuita, era privilégio de poucos, pois a grande maioria não tinha condições de permanecer na escola.

Os estudantes abandonavam a escola, muitas vezes antes de concluir o Ensino Fundamental para trabalhar e prover os meios de subsistência, permanecendo no Ensino Médio apenas os pertencentes às famílias com melhor condição financeira.

O Ensino Médio, modalidade que antes era restrita às elites ou aos grupos sociais mais abastados, tinha como objetivo a preparação para o vestibular e uma formação cultural mais erudita, com vistas a atender às necessidades e aos anseios das famílias brasileiras com maior poder aquisitivo.

Nas últimas décadas esse panorama tem mudado:

Ao Ensino Médio estão chegando outros jovens-adultos. Aqueles que não chegavam, os jovens dos coletivos populares, trabalhadores. Na medida em que a infância-adolescência popular foi tendo acesso ao Ensino Fundamental, aqueles que o completam (ainda uma percentagem distante daqueles que entram nos primeiros anos) tentarão o Ensino Médio com frequência dividindo tempos de estudo e trabalho-sobrevivência. (ARROYO, 2014, p. 60)

O público do Ensino Médio tem se modificado. Os grupos sociais que antes não chegavam a esse nível de escolaridade agora estão chegando. Muitos deles são trabalhadores e precisam equilibrar-se entre rotinas de trabalho e estudo.

Há nesse exemplo uma vantagem indiscutível: o crescimento do acesso a essa modalidade de ensino na educação brasileira. Os grupos sociais menos favorecidos financeiramente agora estão tendo mais possibilidade de frequentar a escola. As oportunidades de escolarização estão se ampliando para um círculo maior de pessoas.

Mas essa situação inédita sugere mudanças no sistema de ensino, uma adequação da escola à realidade de jovens que, muitas vezes, precisam conciliar 
trabalho e estudo. É nítido que esses jovens tem menos tempo de estudo do que aqueles que não precisam trabalhar.

Há também mais dificuldades no processo de aprendizagem uma vez que esses jovens de baixa renda não tem o mesmo capital cultural ${ }^{1}$ que os provenientes das famílias mais ricas. Não dispõem dos mesmos recursos e meios de acesso aos conhecimentos.

Com a universalização do Ensino Médio, o público que frequenta as escolas brasileiras mudou. "Os jovens estudantes que vão chegando ao Ensino Médio são também Outros, de outras origens sociais, raciais, étnicas, dos campos e das periferias" (ARROYO, 2014, p. 55).

Presenciamos a inserção nessa modalidade de ensino, de jovens pertencentes aos grupos mais periféricos ou marginalizados. Por terem outras origens, outros modos de vida, pressupõe-se que tem perspectivas e expectativas diferentes com relação à escola.

O Ensino Médio precisou então, para atender a essas novas juventudes, passar por algumas mudanças, como o respeito à diversidade e à pluralidade.

A Lei de Diretrizes e Bases da Educação Nacional (LDB), número 9394/96 estabelece no seu artigo 35 as finalidades do Ensino Médio:

I - a consolidação e o aprofundamento dos conhecimentos adquiridos no ensino fundamental, possibilitando 0 prosseguimento dos estudos;

II - a preparação básica para o trabalho e a cidadania do educando, para continuar aprendendo, de modo a ser capaz de se adaptar com flexibilidade a novas condições de ocupação ou aperfeiçoamento posteriores;

III - o aprimoramento do educando como pessoa humana, incluindo a formação ética e o desenvolvimento da autonomia intelectual e do pensamento crítico;

IV - a compreensão dos fundamentos científico-tecnológicos dos processos produtivos, relacionando a teoria com a prática, no ensino de cada disciplina. (BRASIL, 1996, p.12)

\footnotetext{
1 Capital cultural - artefatos culturais e educativos; meios de acesso ao conhecimento. (BOURDIEU; PASSERON 2014). Os jovens das famílias mais ricas, tem acesso a mais informações, livros, podem viajar, conhecer outros lugares, museus, enfim, uma diversidade de possibilidades que as famílias mais pobres não podem oferecer aos seus filhos.
} 
Uma das funções do Ensino Médio é a preparação para o vestibular, para o prosseguimento dos estudos. A LDB de 1996 especifica essas funções: aprofundamento dos conhecimentos, preparação para 0 trabalho, aprimoramento do educando e a compreensão dos fundamentos científicos e tecnológicos dos processos produtivos.

O Ensino Médio visa ainda a uma formação mais abrangente, que atenda também às necessidades da população mais pobre, como a preparação para o trabalho e o desenvolvimento de conhecimentos científicos e tecnológicos. Não pode ficar restrito à preparação para o vestibular pois muitos jovens não tem essa pretensão, apesar de não estarem condicionados a fatores puramente econômicos para definir o seu acesso ou não à universidade.

Desse modo, além de preparar o aluno para o prosseguimento dos estudos, deve-se atentar também para as necessidades e expectativas daqueles que não irão frequentar a universidade, para o jovem que cumprirá funções que exigem menos escolaridade, não necessariamente os mais pobres.

Sabemos que muitos dos jovens que frequentam essa modalidade de ensino não darão prosseguimento aos estudos. Portanto, eles precisam ser preparados com noções básicas para atender às necessidades do mercado de trabalho, dominando as tecnologias que possivelmente vão encontrar tão logo adentrem esses espaços.

A LDB também enfatiza valores como a ética e a cidadania, além do objetivo de desenvolver a capacidade de auto formação e de adaptação às necessidades da vida, como o potencial de continuar aprendendo e de ser flexível diante das mudanças.

Conviver em sociedade é outra preocupação do Ensino Médio. Saber se portar, respeitar os espaços, as opiniões e as escolhas dos outros, ser consciente dos seus direitos e deveres são características indispensáveis não só para conquistar espaço em um mercado de trabalho cada vez mais concorrido e exigente, como também para uma convivência pacífica e harmoniosa com os demais membros do seu meio social.

A lei anterior à LDB, que regularizava os ensinos Fundamental e Médio, número 5.692 de 11 de agosto de 1971, não aprofundava muito nessas questões pertinentes aos objetivos do Ensino Médio: "Art. 21. O ensino de $2^{\circ}$ grau destina- 
se à formação integral do adolescente." (BRASIL, 1971). Não há maiores especificações sobre as finalidades dessa modalidade de ensino.

A Resolução CNE/CEB, de 30 de janeiro de 2012, que define as Diretrizes Curriculares Nacionais para o Ensino Médio, reforça o texto da LDB. Em seu artigo 5, parágrafo VII, afirma que 0 Ensino Médio baseia-se no "reconhecimento e aceitação da diversidade e da realidade concreta dos sujeitos do processo educativo, das formas de produção, dos processos de trabalho e das culturas a eles subjacentes;" (BRASIL, 2012, p. 2)

A aceitação da realidade dos sujeitos pressupõe que a escola e o currículo precisam se adaptar a esses novos indivíduos que estão se inserindo nessa etapa de escolarização, atender às suas necessidades, propor um ensino viável para as suas condições de aprendizagem.

De acordo com essas premissas, entende-se que o Ensino Médio deve se voltar para as necessidades reais dos estudantes. Esse estudante não é mais o filho da elite. Estamos agora diante da universalização da educação básica. Precisamos lidar com essa diversidade de indivíduos pertencentes aos mais diversos grupos sociais.

Como atender a tantas necessidades e anseios diferentes e ao mesmo tempo tem sido um desafio muito grande para os profissionais da educação. Desafios esses que só aumentam se levarmos em conta as muitas precariedades do sistema educacional brasileiro.

Muitas discussões sobre currículo tem sido feitas, pois:

Diante da riqueza que chega com essa diversidade, impõem-se as seguintes perguntas: por que a preocupação com o que ensinar-aprender? Que currículos de educação média se colocam como problema nas décadas recentes? Sobretudo, porque ao Ensino Médio estão chegando outros jovens-adultos. Aqueles que não chegavam, os jovens dos coletivos populares, trabalhadores. (ARROYO, 2014, p. 60)

A preocupação com o "ensinar-aprender" é pertinente pois, diante da variedade de interesses, o que agrada a um não agrada ao outro. $O$ adolescente ou jovem² que hoje chega ao Ensino Médio pertence a um grupo social que, há

\footnotetext{
${ }^{2}$ A Lei no 12.852 de 05 de agosto de 2013, a PEC da juventude estabelece a juventude como a faixa etária entre 15 e 29 anos. De acordo com BRASIL, 2013, adolescentes são pessoas com
} 
algumas décadas atrás, abandonava a escola ainda no Ensino Fundamental em decorrência da necessidade de trabalhar.

Muito se tem discutido sobre reforma curricular, construção da aprendizagem significativa, partindo das reais necessidades e/ou interesses dos alunos, tão diferentes entre si e com interesses e necessidades tão discrepantes.

Os sujeitos que frequentam o Ensino Médio pertencem aos mais diversos grupos sociais, desde os grupos sociais mais ricos até os filhos de pessoas pobres que sequer frequentaram o Ensino Fundamental. Muitos são filhos de pais analfabetos ou semianalfabetos.

No entanto, mesmo os filhos dos estratos sociais com menor poder aquisitivo já estão tendo contato com as mídias digitais, com as tecnologias que permeiam as relações sociais, e, consequentemente, o ambiente escolar. Apesar da pouca condição financeira, muitos tem aparelhos de celular modernos e com acesso à internet.

Elaborar um currículo que atenda às necessidades e aos interesses desses alunos tem sido o grande desafio da educação no século $\mathrm{XXI}$, pois, ao passo que eles tem acesso a esses meios de comunicação e de informação, não são devidamente orientados e/ou educados para utilizá-los de forma a obter mais conhecimento.

Apesar do crescente aumento da informação e dos meios de difundi-la e gestioná-la, ocorre paralelamente um aumento da distância entre os que sabem e os que não sabem articulá-las, pensá-las e refleti-las. (BITTENCOURT, 2004, p. 63)

O fato de os jovens terem acesso aos meios de informação não quer dizer, necessariamente, que esses meios sejam bem utilizados, ou que seu uso atinge a finalidade de proporcionar acesso à informação de qualidade. A internet possibilita que qualquer pessoa escreva qualquer coisa, o que torna as informações cada vez mais duvidosas.

idade entre 12 e 18 anos e jovens entre 15 e 29 anos. Na América Latina há um consenso com relação ao fato de que a juventude se estende até os 29 anos. 
A escola, diante desse novo aparato tecnológico, tem mais esse desafio de formar cidadãos capazes de selecionar as informações úteis e transformá-las em conhecimento, fazendo uma leitura crítica de suas reais intenções.

Enfim, são muitos os "sujeitos" que frequentam o Ensino Médio atualmente. Eles tem interesses difusos, múltiplas culturas e múltiplos anseios e necessidades. Como atender a todos eles em uma mesma sala de aula é um dos grandes desafios dessa etapa da educação básica.

\section{A IMPORTÂNCIA DA LEITURA E O ENSINO DE HISTÓRIA}

Diante dessa multiplicidade de sujeitos que frequentam o Ensino Médio, os professores sentem a necessidade de promover mudanças curriculares a fim de atender às demandas dessas juventudes atuais, cada vez mais envolvidos com as tecnologias digitais, mesmo aqueles pertencentes aos grupos sociais com menor poder aquisitivo.

Desenvolver um currículo que seja atrativo aos jovens e ao mesmo tempo atenda às suas perspectivas é de fundamental importância para que o ensino seja eficiente.

As ricas tentativas de inovação curricular encontram motivações nas autorias e na criatividade docente; encontram limites sérios nesse quadro de condições materiais, físicas e de trabalho do viver a condição docente. (ARROYO, 2014, p. 58)

Apesar de muitas propostas de alteração curricular estarem sendo discutidas nos altos escalões do governo, quem põe em prática o sistema educacional é o professor, que apesar dos inúmeros limites que encontra, tem procurado alternativas para incrementar a prática pedagógica a fim de chegar mais próximo do seu aluno, de atrair mais e mais a sua atenção para a importância da escolarização.

A disseminação das tecnologias digitais, ao invés de auxiliar no processo de ensino-aprendizagem, parece ter contribuído para desviar a atenção do aluno dentro da sala de aula (não entraremos nessa discussão). Aparelhos de celular ao invés de serem utilizados como meio de acesso ao conhecimento tem 
dificultado esse processo, uma vez que são utilizados com a finalidade de acessar as redes sociais em momentos nos quais deveria ser utilizado para fins educacionais.

Vivenciamos uma crise no ensino brasileiro, principalmente no ensino público, que é quem atende à população mais pobre. Percebemos que os alunos estão chegando ao Ensino Médio (e cada vez mais saindo dele) em um relativo quadro de analfabetismo funcional.

De acordo com Pinsky, vivemos em "um país cuja população não sabe ler, que, quando sabe, lê pouco, e quando finalmente lê, pouco entende" (PINSKY, 2007, p. 21). Como então alfabetizar esse aluno que já deveria ter chegado ao Ensino Médio alfabetizado?

A falta de compreensão e a dificuldade em interpretar os textos lidos pelos alunos do Ensino Médio é uma reclamação generalizada dos professores. Além disso, percebemos um público cada vez menos envolvido com os livros e, consequentemente, com uma crescente dificuldade em escrever.

Sabemos que a leitura é essencial para o processo de escolarização. Desde o conhecimento das normas da língua, passando pelo desenvolvimento de noções gramaticais, até o desenvolvimento da habilidade de interpretar, que é imprescindível para o bom desempenho do aluno em todas as disciplinas.

De acordo com LAKATOS e MARCONI,

a leitura propicia a ampliação de conhecimentos, abre horizontes na mente, aumenta o vocabulário, permitindo melhor entendimento do conteúdo das obras. Através dela podem-se obter informações básicas ou específicas. (1992, p.15)

Logo, é de fundamental importância o desenvolvimento de hábitos de leitura, pois os benefícios são muitos e ler é condição sem a qual não se desenvolve noções básicas de interpretação.

Sem a construção de um vocabulário rico não é possível compreender o que é lido. Ler é, portanto, um ciclo virtuoso. Quanto mais se lê mais se compreende e mais fácil se torna a leitura ou as leituras posteriores.

Utilizar a literatura com a finalidade de diversificar o currículo e a metodologia do ensino de história pode ser uma alternativa para estimular o gosto pela leitura e usufruir de todos os benefícios que ela proporciona, dentre 
eles, desenvolvimento de noções gramaticais e da capacidade de interpretar e compreender o que foi lido.

Se, conforme dizia Hartog, a forma mais acertada para construir o próprio ponto de vista seria adotar uma abordagem comparativa, poderíamos tentar encontrar uma nova fonte de análise e de trabalho a partir da Literatura.

A convenção da veracidade, própria da História, e a convenção da ficcionalidade, própria da Literatura, permitem-nos estabelecer um método que, seguindo as diretrizes de Hartog, poderá ajudar-nos a elaborar essa abordagem comparativa. (RUIZ, 2007, p. 78)

Ruiz (2007), baseado em Hartog, afirma que pode-se utilizar a Literatura como auxiliar no processo de construção do conhecimento histórico utilizando uma comparação entre os dois campos do saber. Além da comparação, esse método contribuiria para a formação no sujeito, do seu "próprio ponto de vista".

A formação de um ponto de vista a partir da análise e da comparação de documentos diversos é uma das funções do estudo da História, pois, auxilia a formação do ser como sujeito histórico. Esse método é considerado inovador na medida em que impulsiona o sujeito a pensar por si só.

\begin{abstract}
A inovação que ocorre quanto aos objetivos é a ênfase atual ao papel do ensino de história para a compreensão do 'sentir-se sujeito histórico' e em sua contribuição para a 'formação de um cidadão crítico'. (BITTENCOURT, 2004, p. 19)
\end{abstract}

A partir da comparação entre dois tipos de documentos, o histórico e 0 literário, o sujeito consegue, então, "sentir-se sujeito histórico" ao passo que formula o seu próprio pensamento, constituindo-se assim um "cidadão crítico", capaz de pensar por si próprio.

Atingir o objetivo de construir um sujeito crítico, capaz de compreender a sua realidade, tirar suas próprias conclusões no que diz respeito aos eventos históricos do passado e do presente seria então, uma abordagem inovadora no ensino de história.

E por que utilizar a literatura? Teria ela um resultado melhor do que outros métodos? Segundo Leandro Karnal, 
Os textos didáticos apresentam cada vez menos cuidado com a escrita e cada vez mais síntese de conteúdo, sendo, por isso mesmo, textos frios. O uso da literatura pode ser uma superação dessa limitação. (KARNAL, 2007, p. 136)

Os alunos costumam achar as aulas entediantes e enfadonhas. Conseguir estimular o aluno a ler o conteúdo do livro didático tem sido tarefa cada vez mais difícil. Pelo fato de a literatura possuir uma linguagem diferenciada, com 0 objetivo de entreter, ela poderia ser uma leitura mais atraente para o aluno.

Não se pretende substituir textos historiográficos por textos literários, mas utilizar os últimos como auxiliares no processo de compreensão dos primeiros. A leitura de ficção teria a finalidade de atrair a atenção dos alunos para formas de representação do real, estabelecendo uma comparação entre ambas as narrativas.

Outra contribuição que a leitura literária pode oferecer é a contextualização dos acontecimentos estudados. O texto literário é um texto contextualizado, seu enredo se passa em um lugar e tempo específicos. Aprender a contextualizar os acontecimentos, mesmo em um texto literário, auxilia no processo de contextualização também dos eventos históricos.

Essa comparação entre as duas formas de escrita auxilia os alunos na contextualização do conhecimento histórico, o que é de fundamental importância para o aprendizado:

Os jovens e as crianças estão aprendendo História e não dominam o contexto em que o documento foi produzido, o que exige sempre a atenção ao momento propício de introduzi-lo como material didático e à escolha dos tipos adequados ao nível e às condições de escolarização dos alunos. (BITTENCOURT, 2004, p. 329)

É preciso certo cuidado ao se trabalhar com documentos históricos, pois, nem sempre os alunos estão em um grau de escolaridade que lhes permite assimilar, compreender e contextualizar as informações presentes no documento.

Sem a compreensão do contexto que envolve a produção do documento, a produção do conhecimento fica comprometida, com lacunas que precisam ser preenchidas para que $o$ aprendizado seja efetivo. 
Contextualizar e comparar são elementos essenciais na formação da aprendizagem do sujeito, auxiliando no desenvolvimento de noções de criticidade diante dos eventos históricos.

O ensino de história deve contribuir para libertar o indivíduo do tempo presente e da imobilidade diante dos acontecimentos, para que possa entender que cidadania não se constitui em direitos concedidos pelo poder instituído, mas tem sido obtida em lutas constantes e em suas diversas dimensões. (BITTENCOURT, 2004, p. 20)

O ensino de história não cumpre a sua função se não formar um indivíduo capaz de reconhecer-se como agente histórico, como ser capaz de agir diante dos acontecimentos históricos, participar da construção do processo histórico.

Em comunidades menos escolarizadas, costuma-se notar que as pessoas enxergam seus direitos como favores concedidos pelos governantes, pensamento fruto de uma política paternalista.

O ensino de história cumpre seu papel quando desenvolve no sujeito a capacidade de perceber que os direitos que ele usufrui são resultados de lutas e ações sociais.

Faz-se importante desenvolver noções básicas de compreensão e contextualização dos eventos históricos, a fim de formar cidadãos críticos e conscientes de sua função social.

A partir do conhecimento da sua história é que ele passa a ter consciência de si diante da realidade e da diversidade. As habilidades de comparar e contextualizar são essenciais nesse processo de construção do ser pensante, consciente de si, capaz de agir de forma lúcida diante das mudanças sociais.

A leitura é essencial para a formação desse cidadão racional, pois ela amplia a capacidade de percepção da realidade, auxiliando no processo de construção de um ser crítico e pensante.

O ensino de história é fundamental para a formação da cidadania, visto que estuda as transformações sociais e deve estimular o pensamento crítico, visando à construção de uma atuação cidadã na sociedade. Pode e deve, portanto, utilizar-se da literatura para a edificação do pensamento. 


\section{INTERDISCIPLINARIDADE}

O homem vem descobrindo coisas e acumulando conhecimento ao longo de sua existência. O conhecimento científico passou a ser disseminado de forma mais intensa a partir do uso do modelo de imprensa criado por Johann Gutenberg no século $X V^{3}$.

A partir do final do século XVII, com o surgimento das ideias iluministas e da crença no potencial da razão humana, o conhecimento produzido até então foi sintetizado na Enciclopédia pelos franceses Denis Diderot e Jean D'Alembert.

A fragmentação do conhecimento em disciplinas se fez necessária devido à amplitude que o conhecimento científico atingiu com o passar do tempo, tornando impossível um conhecimento aprofundado em todas as áreas por parte de uma pessoa.

A disciplina é uma categoria organizadora dentro do conhecimento científico; ela institui a divisão e a especialização do trabalho e responde à diversidade das áreas que as ciências abrangem. (MORIN, 2003, p. 104)

Assim, de acordo com as necessidades de cada especialidade ou de cada profissão, aprofunda-se mais em determinado tipo de conhecimento.

Para melhor organizar o conhecimento, ele foi dividido em áreas e em disciplinas. Essa divisão foi hierarquizada por Auguste Comte. A teoria positivista estabeleceu um escalonamento das disciplinas em graus de importância para a elaboração do conhecimento científico.

Ora, em razão mesma de seus progressos a partir de Comte, cada uma das ciências fundamentais que ele reconhece (...) explode em disciplinas particulares, entre as quais os sábios se dividem ao se especializarem. O processo de desintegração do saber se acelera. A ciência unitária explode como um obus. E seus fragmentos continuam a dissociar-se em sua trajetória. (JAPIASSU, 1976, p. 49)

3 "A tipografia, inventada na China por Pi-Sheng, em 1041, só chegou à Europa por volta de 1456" (BOULOS JÚNIOR, 2013, p. 279) 
As disciplinas passaram a se subdividir e iniciou-se um processo de superespecialização e fragmentação do saber. Cada um passa a se especializar em um determinado campo do saber, ignorando, muitas vezes, os conhecimentos das outras áreas. Começam a surgir novas ciências derivadas das até então existentes.

Essa hiperespecialização provocou uma espécie de esfacelamento do conhecimento, em que o especialista sabe muito sobre um assunto específico, mas não sabe o básico sobre os demais.

Esse fato remete à passagem de Assim Falava Zaratustra, de Nietzsche (1844-1900), quando ele critica um homem com uma orelha enorme e o resto do corpo pequeno. O homem é considerado um gênio, mas Nietzsche o critica: "Eu, porém, nunca acreditei no povo quando ele me falava de grandes homens, e sustento a minha idéia de que era um aleijado às avessas que tinha pouquíssimo de tudo e uma coisa em demasia." (NIETZSCHE, 2002, p.219)

Os profissionais se especializam em demasia em uma área e ficam deficientes em outras, como um aleijão intelectual.

A crítica à hiperespecialização gerou a necessidade de interligar os diversos tipos de conhecimento. Propôs-se então, uma prática interdisciplinar, em que o conhecimento de uma disciplina pode auxiliar uma outra.

\begin{abstract}
A interdisciplinaridade surgiu no final do século XIX, pela necessidade de dar uma resposta à fragmentação causada pela concepção positivista, pois as ciências foram subdivididas, surgindo várias disciplinas. (BOVO, 1994, p.2)
\end{abstract}

A interdisciplinaridade se apresenta com uma tendência na contramão do esfacelamento das disciplinas, que sofreu muitas críticas por fragmentar 0 conhecimento, separando os campos do saber e isolando-os. Busca a relação existente entre os vários campos do saber, considerando um saber complementar ao outro. As diversas áreas do conhecimento estão relacionadas e interligadas entre si.

Mas, a prática interdisciplinar exige cuidado, a fim de que se cumpram os objetivos estabelecidos para o currículo de cada disciplina em específico. "Cabe ao professor, no momento certo articular teoria e prática, numa forma 
interdisciplinar sem contudo perder os interesses próprios de sua disciplina" (BOVO, 1994, p. 3).

A interdisciplinaridade pressupõe a utilização de conhecimentos de outras disciplinas a fim de facilitar a compreensão dos eventos relacionados a uma disciplina em específico. Deve-se ter o cuidado de não se perder no meio dos conteúdos, fugindo dos objetivos curriculares.

\begin{abstract}
A interdisciplinaridade permite questionar a fragmentação dos diferentes campos de conhecimento. Nessa perspectiva, procuramos tecer os possíveis pontos de convergência entre as várias áreas e a relação epistemológica entre as disciplinas. Com a interdisciplinaridade adquirimos mais conhecimentos dos fenômenos naturais e sociais, que são naturalmente complexos e irredutíveis ao conhecimento obtido quando são estudados por meio de uma única disciplina. As interconexões que acontecem nas disciplinas facilitará a compreensão dos conteúdos de uma forma integrada, aprimorando o conhecimento do educando. (BOVO, 1994, p. 4)
\end{abstract}

O trabalho do professor, sob uma perspectiva interdisciplinar, deve explorar aspectos que a sua disciplina tem em comum com outras, visando uma melhor compreensão dos conteúdos, em decorrência de uma análise mais completa dos fatos, gerando um conhecimento mais complexo.

$\mathrm{Na}$ história, essa prática se fortaleceu a partir do movimento dos Annales na França, em meados do século XX, iniciado por Marc Bloch e Lucien Febvre. "Lucien Febvre proporá aquilo que passou a ser considerado o específico dos Annales, o seu 'espírito': a 'interdisciplinaridade'” (REIS, 2000, p.81).

A partir do movimento dos Annales, a história passou a se abrir para outras disciplinas, que foram chamadas por alguns de disciplinas "auxiliares" ${ }^{\mathrm{da}}$ história. Passou-se a utilizar de forma mais evidente os conhecimentos de disciplinas como a arqueologia, a sociologia, antropologia e diversas outras áreas a fim de elucidar melhor os eventos históricos.

Houve também um questionamento dos documentos oficiais como fonte histórica e, outras fontes cresceram em relevância para a produção do conhecimento histórico.

\footnotetext{
${ }^{4}$ Esse termo sofre algumas críticas por supor uma hierarquização que favorece a disciplina história em detrimento das demais
} 
Surgiu a partir de então, um grupo de historiadores que começou a escrever sobre as relações entre a história e a literatura e a importância desta para a construção do conhecimento histórico.

A literatura passou assim a ser considerada também uma fonte histórica, pois, estabeleceu-se um elo entre a narrativa de ficção e a narrativa literária:

\begin{abstract}
Narrativas de ficção e narrativas de história têm em comum uma mesma maneira de fazer agir seus "personagens", uma mesma maneira de construir a temporalidade, uma mesma concepção de causalidade. (CHARTIER, 2002, p. 14)
\end{abstract}

A partir dos aspectos que os dois campos do conhecimento tem em comum, permite-se então utilizar uma para compreender elementos da outra. $A$ construção da temporalidade na literatura auxilia no processo de construção das noções de temporalidade em história.

Desse modo, considerando as semelhanças entre as duas formas de escrita, apesar das diferenças e particularidades de cada uma, passou-se a utilizar a literatura como meio de acesso para a obtenção ou o aprimoramento do conhecimento histórico.

A utilização do romance para compreender conteúdos de História se justifica, pois,

trabalhar com temas variados em épocas diversas, de forma comparada e a partir de diferentes fontes e linguagens, constitui uma escolha pedagógica que pode contribuir de forma significativa para que os educandos desenvolvam competências e habilidades que Ihes permitam apreender as várias durações temporais nas quais os diferentes sujeitos sociais desenvolveram ou desenvolvem suas ações, condição básica para que sejam identificadas as semelhanças, diferenças, mudanças e permanências existentes no processo histórico. (BRASIL, 2000, p. 26)

A utilização de variadas fontes e linguagens se faz necessária no processo de ensino-aprendizagem pois auxilia no processo de construção das noções de temporalidade, a fim de que os estudantes compreendam as mudanças e permanências inerentes aos processos históricos. 
O romance e sua trama repleta de enredos que se entrelaçam, reforça a concepção de temporalidade do leitor, que se habitua a identificar e distinguir os eventos de curta e os de longa duração, a conjuntura e a estrutura ${ }^{5}$. Lidamos com uma diversidade muito grande de pessoas em uma sala de aula. Cada estudante tem um jeito de pensar e ver as coisas, um jeito diferente de aprender. Uns são mais auditivos e precisam que o professor fale para que eles aprendam. Outros precisam ver, outros escrever, enfim, cada um tem uma forma de aprender.

Para que a escola cumpra a sua função de ensinar, pensando na heterogeneidade de alunos em um mesmo espaço físico, o professor deve se utilizar das mais diversas formas de expressão ou recursos didáticos, seja através da fala, da escrita, das exposições visuais ou das práticas de leitura.

O romance é uma das várias linguagens que podemos utilizar para auxiliar no processo de construção do conhecimento histórico. Além de enriquecer o vocabulário e melhorar as noções de conhecimentos gramaticais, a leitura do romance permite ao aluno desenvolver noções de temporalidade, de sequência dos acontecimentos nos diversos ritmos de duração do tempo.

Presume-se que o aluno pode estabelecer um paralelo entre a fiç̧ão e a realidade, identificando as mudanças e permanências das características da sociedade em um lugar e tempo específicos.

Com base nos Parâmetros Curriculares Nacionais para o ensino de História, a utilização da obra literária é pertinente, pois, desenvolve algumas competências e habilidades, como:

Representação e comunicação - Criticar, analisar e interpretar fontes documentais de natureza diversa, reconhecendo o papel das diferentes linguagens, dos diferentes agentes sociais e dos diferentes contextos envolvidos em sua produção.

\footnotetext{
5 "Os ritmos da duração, conforme descritos por Fernand Braudel, permitem identificar a velocidade em que as mudanças ocorrem e como nos acontecimentos estão inseridas várias temporalidades: a curta duração, a dos acontecimentos breves, com data e lugar determinados; na média duração, no decorrer da qual se dão as conjunturas, tendências políticas e/ou econômicas, que, por sua vez, se inserem em processos de longa duração, com permanências e mudanças que parecem imperceptíveis. É o ritmo das estruturas, tais como a constituição de amplos sistemas produtivos e de relações de trabalho, as formas de organização familiar e dos sistemas religiosos, a constituição de percepções e relações ecológicas estabelecidas na relação entre o homem e a natureza." (BRASIL, 2000, p. 25)
} 
Contextualização sócio-cultural - Situar as diversas produções da cultura - as linguagens, as artes, a filosofia, a religião, as ciências, as tecnologias e outras manifestações sociais - nos contextos históricos de sua constituição e significação. (BRASIL, 2000, p. 28)

A habilidade de interpretar documentos é essencial para 0 desenvolvimento do educando, pois, a grande maioria deles tem acesso a diversos tipos de documentos que a tecnologia digital proporciona, mas, percebe-se que os estudantes tem muita dificuldade em interpretar essas informações.

A habilidade de contextualização está diretamente relacionada com a de interpretar, pois para uma boa compreensão dos fatos é preciso interpretá-los dentro de um determinado contexto.

Uma obra de arte não tem o mesmo significado fora de seu contexto. Guernica, de Pablo Picasso, por exemplo, não pode ser compreendida se não for relacionada com a guerra civil espanhola.

Saber interpretar e contextualizar os fatos é de fundamental importância para a realização de uma leitura adequada da realidade histórica.

A literatura, como manifestação artística, está situada em um

determinado contexto histórico. É, portanto, fruto de sua sociedade, representa uma forma de pensar e de agir no período em questão.

A proposta de trabalho interdisciplinar entre a história e a literatura é relevante no sentido de que o texto literário contribui para o desenvolvimento de habilidades necessárias para a compreensão dos processos históricos.

\section{A HISTÓRIA E A LITERATURA: DIÁLOGOS POSSÍVEIS}

Desde que a história existe como disciplina, diversos autores questionam a proximidade desta com a literatura, visto que ambas tratam de fatos que aconteceram com alguém, em um determinado lugar e em um período específico. 
Desse modo, apesar de a literatura ser fictícia e a história ter o seu compromisso com a realidade, ambas retratam uma determinada sociedade, com seu modo de viver, seus conflitos e suas ideias, de modo que as duas podem ter muito em comum.

Leopoldo Von Ranke, o fundamentador da história como disciplina, já via semelhanças entre estes dois campos do saber. "Em Ranke, a mão modeladora do artista literário nunca se distancia do labor construído do historiador" (GAY, 1990, p. 66). Neste caso, o literário, visto como artista, produz algo parecido com o historiador, já enquadrado na categoria de "trabalhador"6.

A proximidade entre os dois campos do conhecimento é evidente, pois ambos retratam um grupo de pessoas específico, vivendo em um lugar e um tempo determinados. A forma de retratar essa sociedade é que muda de acordo com os métodos singulares de cada ciência.

O que diferencia a História da literatura é a finalidade de cada uma. Enquanto a primeira tem o objetivo de informar, transmitir conhecimento sobre $o$ ocorrido com os homens no passado, a segunda tem fins de entretenimento. De acordo com Roger Chartier,

como Veyne, de Certeau salienta que toda escritura histórica, seja qual for sua forma, é uma narrativa que constrói seu discurso de acordo com processos de 'narrativização' que reorganizam e reordenam as operações da pesquisa. Mas distanciando-se de Veyne, ele sugere um duplo deslocamento. O que determina as escolhas dos historiadores (no recorte dos objetos, na preferência dada a uma forma de trabalho, na eleição de um modo de escritura) é muito mais o lugar que eles ocupam na 'instituição do saber' do que o prazer de sua subjetividade. $O$ que dá coerência ao seu discurso não é, ou não somente, o respeito às regras próprias aos gêneros literários que eles empregam, mas as práticas específicas determinadas pelas técnicas de sua disciplina. (CHARTIER, 2002, p. 102)

Para Chartier, enquanto o historiador tem a função de produzir conhecimento, a do literário é produzir entretenimento. A narrativa histórica afasta-se da narrativa literária no que diz respeito à sua função. Ambas são

${ }^{6} \mathrm{O}$ historiador tem a função de produzir conhecimento enquanto o literário produz entretenimento. $\mathrm{O}$ caráter do trabalho do historiador requer mais austeridade. 
narrativas mas apresentam funções e estilos diferentes no que concerne aos modos de fazer de cada uma.

O uso da literatura como fonte histórica se popularizou com a terceira geração do movimento dos Annales na França, a partir das décadas de 1970 e 1980, período em que a história se abriu para novas perspectivas, dialogando com outros campos do saber, fugindo de um ensimesmamento que vinha sendo muito criticado e discutido.

Houve, a partir de então, uma "tomada de consciência dos historiadores de que seu discurso, seja qual for sua forma, é sempre uma narrativa" (CHARTIER, 2002, p. 85), visto que a função da história é sempre a de narrar acontecimentos do passado.

Esse "retorno da narrativa"7 foi consequência da crise de paradigmas que se fez presente no campo da história na segunda metade do século $X X$ e proporcionou uma série de mudanças no seu campo de atuação, abrindo espaço para novas abordagens, a partir da necessidade de criar novos meios de compreender os processos de mudanças sociais.

Assim, o reconhecimento da história como narrativa proporcionou ao historiador recorrer tanto à literatura quanto a outras fontes, como a arqueologia, a geografia e outros conhecimentos muito úteis ao seu trabalho.

A "tomada de consciência" se deu a partir do desenvolvimento dos estudos do imaginário, aproximando assim, a narrativa histórica da narrativa literária. Esse momento marcou o que alguns historiadores chamam de retorno da narrativa ao campo da história, se é que ela em algum momento se afastou da história, pois,

lendo bem 'l'opération historiographique'1, fica claro que o diagnóstico, feito alguns anos mais tarde, que caracteriza a evolução mais recente da história como um 'retorno do narrativo', é um amplo simulacro. Seja o que for, a história é sempre narrativa, mas narrativa particular, já que visa a produzir um saber verdadeiro. (CHARTIER, 2002, p. 158)

\footnotetext{
7 "L. Stone argumenta na seguinte direção: para ele, os Annales interromperam, ao abandonarem a forma narrativa, uma tradição de mais de vinte séculos. Eles tinham abandonado a narração e trocaram-na por uma história estrutural quantitativa. Entretanto, ele constata, os mais novos historiadores da própria "escola" dos Annales já estavam fazendo uma história narrativa, novamente, sem o confessarem" (REIS, 2000, p. 134)
} 
Chartier acredita que a narrativa nunca se afastou da história. Para ele não existe o que muitos historiadores chamam de "retorno da narrativa" ao campo da história porque a narrativa não pode ser dissociada do seu discurso, porém é uma narrativa diferente da literária devido ao seu compromisso com o real.

Se a narrativa, em algum momento, deixou ou não de fazer parte da "operação historiográfica"8, não pretendo discutir aqui. O que importa é que ela se faz presente hoje no processo de construção do conhecimento histórico.

A literatura passou a fazer parte desse processo a partir de um momento de renovação da história.

Segundo José Carlos Reis (2000, p. 135), essa renovação "se liga também ao interesse dos novos historiadores em retomarem o contato com o público culto não-especializado, que os tinha abandonado, com seu texto cifrado e esotérico, produzido para a circulação interna".

Desse modo, a aproximação da história com a literatura teria a finalidade de popularizar a primeira, que havia se distanciado do público devido à sua complexidade, à sua linguagem de difícil compreensão. O caráter intrínseco da produção historiográfica foi muito criticado pela historiografia do final do século $\mathrm{XX}$, que reconheceu o "ensimesmamento" da produção historiográfica, com fins unicamente academicistas. A literatura constituiu-se então, como um meio de fugir do ensimesmamento da história.

A literatura pode ser utilizada como uma ferramenta de investigação que auxilia o historiador no seu trabalho de reconstituição dos eventos históricos. Dessa forma, através do estudo da literatura podemos compreender a forma de viver de certo grupo social e, principalmente, o discurso que prevaleceu na mente da população em uma determinada sociedade, ou seja, no seu imaginário ${ }^{9}$.

O ponto de encontro de ambas as narrativas está no fato de a literatura refletir os modos de pensar e agir das pessoas em seu "lugar social"10, ela é o

\footnotetext{
$8 \mathrm{O}$ trabalho do historiador ao fazer história. "O que fabrica o historiador quando 'faz história'? para quem trabalha? Que produz?" (CERTEAU, 1982, p. 65)

${ }^{9}$ Michel de Certeau utiliza o termo imaginário no sentido de construção da imaginação; algo que se imagina sobre uma determinada sociedade a partir das informações que a história oferece. Sandra Pesavento caracteriza o imaginário como um conjunto de representações.

10 "Lugar de produção socioeconômico, político, cultural" (CERTEAU, 1982, p. 66).
} 
reflexo, como toda manifestação artística, das dúvidas e anseios de quem a produziu, no exato lugar e tempo em que foi produzida.

A literatura sofre "a influência da religião, dos costumes e das leis" (COMPAGNON, 2006, p. 199), ou seja, a literatura retrata todos os eventos que marcam o modo de vida de um determinado grupo social: mostra como viviam essas pessoas, as práticas religiosas, os modos de se vestir, de se comportar, de se relacionar, entre outras coisas.

Ao lermos uma obra literária, situamo-la em um tempo e espaço definido, ou seja, relacionamo-la com a sociedade que gerou tal obra, pois ela é seu fruto, tal como a história, ela é fruto de quem a produziu e retrata as características dessa sociedade.

A literatura se apresenta como uma nova fonte histórica, através da qual podem ser estudados novos problemas, ou velhos problemas através de novas abordagens. Dessa forma, com esse tipo de fonte histórica, podemos encontrar dados dispersos ou mesmos esquecidos por outras fontes.

Assim, a leitura de um romance, crônica ou poesia retrata o "gesto que liga as ideias aos lugares" (CERTEAU, 1982, p. 65) que, segundo Michel de Certeau, é "um gesto de historiador" (Ibid, p. 65). A representação literária remete a um lugar, produz no leitor uma ideia sobre determinada sociedade, época ou lugar, por isso liga "as ideias aos lugares".

As descrições presentes no romance, por exemplo, levam o leitor a imaginar a vida na época retratada. Ele, então, constrói na sua mente o universo das representações, o que facilita a compreensão dos processos históricos desenvolvidos nesse período; assim, ao estudar a história, o leitor de literatura terá construída na sua mente formas de representação do real.

De acordo com BOURDIEU, apud CHARTIER 2002, "a representação que os indivíduos e os grupos fornecem inevitavelmente através de suas práticas e de suas propriedades faz parte integrante de sua realidade social" p. 177.

A literatura, parafraseando Bourdieu, inevitavelmente fornece informações sobre o real. Há no romance elementos da realidade social, características dessa sociedade presentes na narrativa literária. Ao longo do romance, vamos percebendo como era a vida nesse período e nesse lugar, como as pessoas se comportavam. 
O conceito de representação aqui utilizado remete ao conceito de Roger Chartier: "o conjunto das formas teatralizadas e 'estilizadas' (segundo a expressão de Max Weber) graças às quais os indivíduos, os grupos, os poderes constroem e propõem uma imagem de si mesmos." CHARTIER, 2002, p. 177.

A literatura é vista como uma teatralização do real. Sabe-se que não retrata fatos verídicos, mas serve de base para se ter uma noção de como as coisas aconteciam em uma determinada sociedade, visto que ela representa, teatraliza a realidade, o que fornece informações úteis para o trabalho de historiador, que é o de investigar a realidade passada. É nessa perspectiva que é utilizado o termo "representação" neste trabalho.

Segundo Sandra Jatahy Pesavento, "a representação não é uma cópia do real, sua imagem perfeita, espécie de reflexo, mas uma construção feita a partir dele" (PESAVENTO, 2012, p. 20). Sabemos que literatura não é história, mas, é possível construir a história através da representação literária, visto que a literatura reflete imagens que podem ser apropriadas pela historiografia a fim de elucidar elementos que outras fontes históricas não são capazes de reconstituir.

Se na narrativa literária pode se encontrar um "lugar social", logo, esta pode ser apropriada pelo historiador a fim de ajudá-lo a encontrar respostas, preencher lacunas a respeito dos modos de vida das pessoas do "lugar social" em que ele estuda.

O historiador pode recorrer à literatura para trazer à tona questões a respeito do quotidiano, do modo de vida das pessoas e do local onde se passa a trama romanesca.

A literatura, pela sua força imaginária que instiga a representação da realidade, tem o poder de reconstituir aspectos da vida cotidiana, desvendar contradições e revelar divergências presentes nas relações sociais e nas suas representações.

Dessa forma, a literatura é uma fonte da qual o historiador pode se utilizar para compreender a história de um povo, sua cultura, hábitos e atitudes, ou seja, o seu cotidiano; ela pode servir para interpretar valores, concepções, sentimentos, enfim, apropriar-se de elaborações dos acontecimentos recolhidos, imaginados, idealizados.

História e literatura dialogam entre si, visto que personagens e tramas literárias representam indivíduos que, se não existiram, poderiam ter existido em 
uma determinada sociedade e em uma determinada época. Personagens e tramas literárias são para a historiografia uma representação do possível, do que poderia ter acontecido, uma vez que podem ser contextualizadas historicamente.

Nos escritos literários, percebem-se os elementos históricos e as características do período e do local em que o autor está inserido, bem como a visão que ele tem a respeito das temáticas presentes no romance. Essa visão reflete um modo de pensar de uma ordem social, em um dado momento, em um lugar específico. É esse tripé (Quem? Onde? Quando?) que sustenta o trabalho do historiador e é nele que este deve se apoiar ao analisar uma obra literária.

Segundo Andrade (1996), história e literatura aproximam-se principalmente pela importância do testemunho literário para a pesquisa histórica. Através da sua riqueza de dados, a literatura possibilita captar aspectos do cotidiano, por meio de suas representações, auxiliando na análise histórica.

Ao lermos, por exemplo, as obras de José de Alencar, escritas no século $\mathrm{XIX}$, percebemos em seus romances e crônicas os valores burgueses presentes na sociedade de corte durante o Segundo Reinado, que levavam aos casamentos por conveniência.

Nas entrelinhas de uma história de amor, de uma paixão mal resolvida, de uma epopeia ou de uma aventura, percebem-se características sociais, da ideologia ${ }^{11}$ do autor, que revela suas ideias, a ordem social a qual ele pertence, dentre outras coisas.

Os romances indianistas de José de Alencar refletem a necessidade de criação de uma identidade nacional, o índio alencariano é o primeiro herói nacional brasileiro. Essa construção literária é reflexo da necessidade brasileira do século XIX de construção de uma identidade nacional, notável no ufanismo de Alencar. Sobre o mesmo tema do ufanismo, poderíamos notar ainda, para efeito de distinção de temporalidades, a personagem de Lima Barreto em Triste Fim de Policarpo Quaresma, escrito na Primeira República num estilo e concepção completamente diferentes do romantismo do século XIX.

Muitos são os romances oitocentistas, de diversos autores, que remetem ao nacionalismo, o que nos leva a crer, pautados em outros conhecimentos

${ }^{11}$ Ideologia como conjunto de ideias, com base nas ideias de Antonio Gramsci. 
históricos, em outras fontes historiográficas, que a sociedade brasileira ansiava pela construção de sua identidade como nação recém-independente.

Essas percepções preenchem lacunas a respeito do modo de vida das pessoas descritas na obra literária, reforçam o que as outras fontes históricas constatam ao analisar o período pós-independência.

$\mathrm{Na}$ medida em que a literatura reflete os modos de vida de uma determinada sociedade, ela interessa à história. Cada um dos dois campos narrativos tem seus interesses e suas peculiaridades. A história tem um compromisso com o real que a literatura não tem. "Enquanto a historiografia procura o ser das estruturas sociais, a literatura fornece uma expectativa do seu vir-a-ser" (SEVCENKO, 1999, p. 120).

A área de interesse da história é a realidade, o que aconteceu e pode ser comprovado, baseado em fontes aceitáveis pelos especialistas, já a literatura constitui uma representação do possível, algo que poderia ter acontecido e ficado às margens da história, assim, "para historiadores a literatura é enfim testemunho histórico" (CHALHOUB, PEREIRA, 1998, p.7), testemunho de algo que poderia ter acontecido, se observadas as características sociais do período retratado, visto que representa atitudes de possíveis agentes históricos.

Enquanto a narrativa histórica tem a pretensão de aproximar-se da verdade sobre o que aconteceu, a narrativa literária conta aquilo que poderia ter acontecido em um determinado tempo e espaço, com determinadas pessoas. A literatura conta o que a história não pôde/pode comprovar.

O historiador, então, pode apropriar-se da literatura para fins históricos.

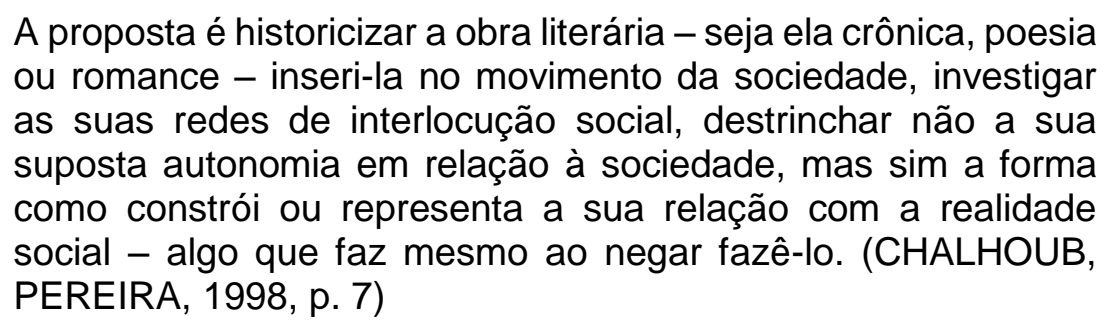

Visto que a obra literária trata de acontecimentos que, mesmo fictícios dentro do romance, são acontecimentos históricos. Há um paralelo estabelecido entre personagens de romances e personagens da vida real. 
Ao descrever lugares, gestos, valores e crenças dos personagens, o autor da trama romanesca retira tais valores da sociedade em que descreve, a trama está situada histórica e socialmente, pois "qualquer obra literária é evidência histórica, objetivamente determinada - isto é, situada no processo histórico-, logo, apresenta propriedades específicas e precisa ser adequadamente interrogada" (CHALHOUB, PEREIRA, 1998, p. 7).

Saber interrogar adequadamente a obra literária é essencial para que esta obra atenda aos interesses do historiador, para que esta se torne recurso pertinente à historiografia. Sabendo interrogar textos literários, "de resíduos de papéis [...] o historiador faz outra coisa: faz deles a história" (CERTEAU, 1982, p. 79).

Mas é preciso observar as diferenças entre as duas áreas do conhecimento, considerar que há "variações entre as representações literárias e as realidades sociais que elas representam deslocando-as sobre o registro da ficção e da fábula." (CHARTIER, 2002, p. 259)

Ao interrogar a obra literária, o historiador precisa estar atento para as diferenças entre os dois campos do saber, pois, uma é ficção e a outra tem compromisso com o real. A história precisa comprovar o que diz, a literatura não, literatura é entretenimento.

A título de exemplo, O Homem que venceu Auschwitz, de Denis Avey e Rob Broomby, uma narrativa biográfica, retrata, de forma peculiar, os horrores da Segunda Guerra Mundial, pois, além de narrar o dia-a-dia de um preso em um campo de concentração nazista, suas estratégias para sobreviver, seu completo desconhecimento sobre o desenrolar da Guerra, sua leitura transporta o leitor para o campo de concentração e para o campo de batalha.

Analisar uma obra como esta, mostra uma realidade que nenhum livro didático de história consegue mostrar sobre esse evento. Sua leitura, aliada aos conhecimentos históricos estudados e discutidos em sala de aula, levam o aluno a ter outra visão desse episódio do século XX. Precisamos do testemunho literário das pessoas que vivenciaram esses acontecimentos para termos a verdadeira dimensão desses atos.

\section{CONCLUSÃO}


A literatura pode ser sim utilizada como ferramenta para auxiliar no processo de construção do conhecimento histórico na medida em que ambas as áreas tem múltiplos aspectos em comum, como, por exemplo, as diversas temporalidades presentes nas suas narrativas.

Não só é possível utilizar a literatura nas aulas de história como é muito pertinente e enriquecedora essa prática, desenvolvendo nos alunos as habilidades de correlacionar conhecimentos de áreas diferentes, ler, compreender e contextualizar os eventos históricos a partir da representação literária.

\section{REFERÊNCIAS}

ANDRADE, Celeste Maria Pacheco. A literatura no ensino da história da Bahia: a obra de Jorge Amado. Sitientibus. Feira de Santana, n.14, p. 09-21, 1996.

ARROYO, Miguel G. Repensar o ensino médio: Por quê? In: DAYRELL, Juarez; CARRANO, Paulo; MAIA, Carla Linhares (org.). Juventude e ensino médio: sujeitos e currículos em diálogo. Belo Horizonte: Editora UFMG, 2014.

AVEY, Denis; BROOMBY, Rob. O homem que venceu Auschwitz: Uma história real sobre a Segunda Grande Guerra. Rio de Janeiro: Nova Fronteira, 2011.

BARRETO, Lima. Triste Fim de Policarpo Quaresma. Rio de Janeiro: Record, 1998.

BITTENCOURT, Circe Maria Fernandes (org.). O saber histórico na sala de aula. São Paulo: Contexto, 2004.

Ensino de história: fundamentos e métodos. São Paulo: Cortez,

2004.

BOULOS JÚNIOR, Alfredo. História, sociedade \& cidadania, 1a ano. São Paulo: FTD, 2013.

BOURDIEU, Pierre; PASSERON, Jean Claude. A Reprodução: elementos para uma teoria do sistema de ensino. Petrópolis: Vozes, 2014.

BOVO, Marcos Clair. Interdisciplinaridade e transversalidade como dimensões da ação. Revista Urutágua. Revista acadêmica multidisciplinar número 07 ago/set/out/nov - Maringá, Paraná: 1994. ISSN 1519.6178 Retirado de: http://www.uem.br/urutagua/007/07bovo.htm Acesso em: 15 de julho de 2018 
BRASIL, Ministério da Educação. Resolução no 2, de 30 de janeiro de 2012. (Resolução $\mathrm{CNE} / \mathrm{CEB}$ ).

Retirad

de: http://portal.mec.gov.br/index.php?option=com_docman\&view=download\&alias =9917-rceb002-12-1\&ltemid=30192 Acesso em 25 de junho de 2018.

Presidência da República. Lei no 12.852 de 5 de agosto de 2013. Retirado de: http://www.uje.com.br/estatutodajuventude/ Acesso em 08 de julho e 2018.

Presidência da República. Lei no 5.692 de 11 de agosto de 1971. Retirado de: http://www2.camara.leg.br/legin/fed/lei/1970-1979/lei-5692-11agosto-1971-357752-publicacaooriginal-1-pl.html Acesso em: 26 de junho de 2018.

$\begin{array}{ccc}\text { _. Presidência da República. Lei no } 9.394 \text { de } 20 \text { de dezembro de } \\ \text { Retirado } & \text { de: } & \text { https://proplan.ufersa.edu.br/wp- }\end{array}$ content/uploads/sites/7/2014/09/LEI-n\%C2\%B0-9.394-de-20-de-dezembro-de1996.pdf Acesso em 25 de junho de 2018.

, Secretaria de Educação Básica. Formação de professores do ensino médio, etapa I - caderno II: o jovem como sujeito do ensino médio. Curitiba: UFPR/ setor de educação, 2013.

Secretaria de Educação Média e Tecnológica. Parâmetros Curriculares Nacionais para o Ensino Médio: parte IV - Ciências Humanas e suas tecnologias. 2000. Retirado de: http://portal.mec.gov.br/seb/arquivos/pdf/cienciah.pdf Acesso em: 15 de abril de 2018.

; PEREIRA, Leonardo Affonso de M. (orgs). A história contada. Capítulos de história social da literatura no Brasil. Rio de Janeiro: Nova Fronteira, 1998.

CHARTIER, Roger. À beira da falésia: a história entre certezas e inquietude. Porto Alegre, Editora da Universidade Federal do Rio Grande do Sul, 2002.

CERTEAU, Michel de. A Escrita da História. Rio de Janeiro: Forense Universitária, 1982.

COMPAGNON, Antoine. O Demônio da Teoria - literatura e senso comum. Belo Horizonte: EDUFMG, 2006

GAY, Peter. O Estilo na História. São Paulo: Companhia das Letras, 1990. JAPIASSU, Hilton. Interdisciplinaridade e patologia do saber. Rio de Janeiro: Imago, 1976.

KARNAL, Leandro (org.). História na sala de aula: conceitos, práticas e propostas. São Paulo: Contexto, 2007. 
LAKATOS, Eva Maria e MARCONI, Marina de Andrade. Metodologia do trabalho científico: procedimentos básicos, pesquisa bibliográfica, projeto e relatório, publicações e artigos científicos. São Paulo: Atlas, 1992.

MORIN, Edgar. A cabeça bem feita: repensar a reforma, reformar 0 pensamento. Rio de Janeiro: Bertrand Brasil, 2003.

NIETZSCHE, Frederico. Assim falava Zaratustra. Versão para ebook: eBooksBrasil.com, 2002.

PESAVENTO, Sandra Jatahy. História e história cultural. Belo Horizonte: Autêntica, 2012.

PINSKY, Jaime \& PINSKY, Carla. Por uma História prazerosa e conseqüente. In: KARNAL, Leandro (org.). História na sala de aula: conceitos, práticas e propostas. São Paulo: Contexto, 2007.

REIS, José Carlos. Escola dos Annales: a inovação em história. São Paulo: Paz e Terra, 2000.

RUIZ, Rafael. Novas formas de abordar o ensino de história. In: KARNAL, Leandro (org.). História na sala de aula: conceitos, práticas e propostas. São Paulo: Contexto, 2007.

SEVCENKO, Nicolau. Literatura como missão: tensões sociais e criação cultural na Primeira República. São Paulo: Brasiliense, 1999. 